\title{
Zum Nachweis der Gonokokken im Harn und den Sekreten.
}

\author{
Von
}

\section{Posner (Berlin).}

Zu wiederholten Malen habe ich bereits auf die Verwertbarkeit der sog. Quenselschen Lösung (Methylenblau-Kadmiumchlorid) für die Untersuchung der Harnsedimente hingewiesen ${ }^{1}$ ). Als ihr besonderer Vorzug wurde von allen, die sich mit dieser Methode beschäftigt haben, die außerordentliche Schnelligkeit und Sicherheit anerkannt, mit welcher sie Zellen und Kerne, Zylinder und präzylindrische Gebilde zur Anschauung bringt, ohne daß die zarten Formen durch die Präparation eine wesentliche Änderung erfahren. Gerade auf die Übereinstimmung dieser Resultate mit den Ergebnissen der so exquisit konservativen Dunkelfeldbeleuchtung, über welche ich vor 10 Jahren berichtete ${ }^{2}$ ), glaubte ich besonderen Wert legen zu dürfen.

In den bisherigen Mitteilungen ist vorwiegend von diesen, für die Morphologie der Harnsedimente wichtigen Befunden die Rede gewesen. Weniger Aufmerksamkeit haben die bakteriologischen Verhältnisse gefunden; und es kann auch kaum einem. Zweifel unterliegen, daß, ganz allgemein gesprochen, für deren Studium die übliche Färbung des Trockenpräparats weitaus den Vorzug verdient. Namentlich Differenzierungen, wie sie z. B. für die Erkennung der Tuberkelbacillen notwendig sind, kann man lediglich auf diesem Wege erzielen. Immerhin hat Quensel bereits in seiner grundlegenden Arbeit bewiesen, daß auch die im Harnsediment befindlichen Mikroorganismen sich durch seine vitale Färbung gut darstellen lassen; seine vortrefflichen Abbildungen zeigen Kolibacillen, Streptobacillen, Kokken aufs deutlichste. Insbesondere tritt ein Verhalten scharf hervor, welches unter Umständen einen erheblichen diagnostisehen Wert beanspruchen kann: da bei der Quenselfärbung der Zellleib sehr gut erhalten bleibt, ist die Frage, ob etwa vorhandene Mikroorganismen in tra - oder e xtra cell ulär

1) Vgl. C. Posner, Zur Mikroskopie der Harnsedimente. Zeitschr. f. Urol. 1920. - O. Beyse, Fortschritte auf dem Gebiet der Harnsediments-Untersuchung. J. D. Berlin 1920 (dort Literatur). - E. Kraft, Beitrag zur Technik der Harn-Mikroskopie. Apotheker-Zeitung. 16. 1920.

2) Posner, Harnfilamente und Harnzylinder. Dermatol. Studien. 20. Unna-Festschrift 1910. 
belegen sind, mit größter Sicherheit zu beantworten, und man durfte erwarten, daß dieser Umstand vielleicht für die Erkennung von Gonokokken von praktischem Wert sein könnte.

Von den Autoren, die sich bisher hierzu geäußert haben, ist wesentlich nur Beyse in seiner Inauguraldissertation darauf eingegangen; er sagt, „daß deren intracelluläre Lagerung in der plastisch sich bewegenden Leukocyten-Kugel besonders augenfällig wird". Ich habe seit längerer Zeit ebenfalls mein Augenmerk hierauf gerichtet und glaube, nach immer wiederholten Versuchen, speziell für diesen Zweck die in Rede stehende Färbungsmethode empfehlen zu sollen.

Dies bezieht sich natürlich weniger auf die Untersuchung des eitrigen Harnröhrensekrets selbst; hier ist die Färbung des Trockenpräparats so einfach und so schnell erledigt, daß man keinen Grund hat, eine andere Methode zu suchen; auch früher hat man ja, z. B mit Neutralrot, eine Vitalfärbung mit Erfolg angewandt, sie aber zugunsten der Trockenfärbung verlassen, um so mehr, als ja nur letztere die Frage der GramPositivität zu entscheiden gestattet. Nur zur Kontrolle der Leistungsfähigkeit mag man gelegentlich einen Vergleich zwischen den verschieden behandelten Präparaten anstellen. Es wird sich dabei u. a. auch wieder die Tatsache ergeben, daß die Zellkerne sich der Quenselfärbung gegenüber etwas anders verhalten als bei der Trockenfärbung (etwa mit Ma y-Grünwald): in letzterer nehmen sie fast gleichmäßig die 'Tinktion an - in der ersteren erscheint nur ein Teil sofort blau gefärbt, während die übrigen sich erst langsam und schwach mit dem Farbstoff durchtränken. Dieser Umstand ist bei Vitalfärbungen schon früheren Beobachtern (z. B. Björling) aufgefallen; worauf er beruht, wird bei anderer Gelegenheit zu erörtern sein.

Wichtiger ist die Anwendung der Quensel-Methode bei Harnfilamenten. Thre Vorbereitung zur Trockenfärbung ist bekanntlich zeitraubend, unbequem und elurch das intensive Verreiben auch mit Veränderungen der zelligen Elemente verbunden. Hier führt der Zusatz. von Kadmium-Methylenblau bedeutend schneller zum Ziel; ich habe sehr häufig den Nachweis von Gonokokken mit einer früher nicht gekannten Sicherheit auf diese Weise erbringen können. Die Schönheit der Bilder wird dabei durch die Anfärbung der Grundsubstanz noch beträchtlich erhöht.

Ein noch günstigeres Objekt bildet das Prostatasekret, welches überhaupt für die Anwendung der Quenselmischung sehr geeignet ist. Die Unterscheidung der verschiedenen Körner wird namentlich dann sehr deutlich und eindrucksvoll, wenn man stark sudanhaltige Mischungen benutzt: es lassen sich dann die lipoiden und nichtlipoiden Granula auf den ersten Blick unterscheiden. Die vitale, auch von Björling angewandte Tinktion ist jedenfalls der Herstellung von Trockenpräparaten 
weit vorzuziehen; bei letzterer Methode erhält man sehr oft nur unklare und verwaschene Bilder. Daher werden die Gonokokken bei akuter und namentlich bei ehronischer Prostatitis so oft übersehen, obwohl sie sicherlich hier gerade für die matrimoniale Infektion eine.große Rolle spielen: nicht mit dem spärlichen Harnröhrensekret, sondern mit dem Sperma gelangen sie in die weiblichen Genitalien. Nur so erklären sich die Infektionsfolgen, die sich nicht wie sonst als Kolpitis oder Urethritis, sondern alsbald im Gebiet des Uterus und seiner Adnexe zeigen.

Auch bei bakteriologiseher Untersuchung der Harnsedimente ergibt die gleichzeitige Fixation und Färbung, wie sie die KadmiumMethylenblaulösung ermöglicht, oft überraschend günstige Resultate. Man sieht auf diese Weise häufiger als sonst die Lagerung der Mikroorganismen innerhalb der Zelle - wird sich aber natürlich hüten müssen, alle intracellulären Kokken gleich als Gonokokken anzusprechen. Zur ersten Orientierung ist diese Tinktion sehr nützlich. Beyse und ich haben vorgeschlagen, sie beim Harnsediment auch in der Art vorzunehmen, daß man einen Tropfen des Zentrifugates direkt auf dem Objektträger mit der Farblösung versetzt. Wichtig ist freilich hierbei das richtige Mischungsverhältnis: der Sedimenttropfen muß klein, die Farbmenge relativ groß sein, andernfalls nimmt die Tinktion zuviel Zeit in Anspruch und die Intensität der Färbung wird zu gering. Im allgemeinen färben sich die Bakterien rascher als die Zellkerne oder sonstigen plasmatischen Beimengungen.

Ich möchte hieran noch einige Bemerkungen über Versuche mit anderen Farbstoffen knüpfen. Zunächst dachte ich, durch Zuzatz von Eosin vielleicht eine Doppelfärbung zu erzielen - doch ist dies bisher nicht gelungen. Dagegen hat sich gezeigt, daß der Zusatz von $\mathbf{F} \mathbf{u}$ chsin oder noch besser die Frsetzung des Methylenblau durch diesen Körper brauchbare Bilder ergab. Die Farbmischung bereits, noch besser aber die Fuchsinkadmiumlösung ermöglicht nämlich, was gerade beim Fahnden auf Gonokokken wünschenswert sein kann, eine bessere Unterscheidung der mononucleären Leukocyten von kleinen einkernigen Epithelzellen, welche bei Anwendung der Quenselschen Lösung sehr ähnliche Bilder zeigen. Quen sel selbst setzt sehr umständlich auseinander, daß diese beiden Zellarten eigentlich keine wirklichen Differenzen aufweisen, so daß es oft ganz unmöglich sei, zu sagen, ob man es mit Nierenelementen oder mit Leuko- bzw. Lymphocyten zu tun habe, - er hält es geradezu für wahrscheinlich, daß die Angaben von Senator und Schnütgen über das Vorkommen der letzteren Zellen bei Nephritis auf einer Verwechselung mit kleinen, aus den Harnkanälchen stammenden Epithelzellen beruhen. Das Dunkelfeld läßt, wie auch Beyse richtig betont hat, solche Unterscheidung zu; denn bei seiner Anwendung 
464 C. Posner: Zum Nachweis der Gonokokken in Harn und den Sekreten.

erscheinen die Leukocytenkerne tiefschwarz, optisch leer, während die Kerne der Epithelzellen von einer feinen, reflektierenden Membran umgeben sind. Hier scheint das Fuchsin wertvolle Dienste zu leisten, da es die Eigenschaft hat, die Leiber der Epithelzellen viel intensiver zu röten als jene der Leukocyten. Dies tritt namentlich bei Untersuchung an Harnfilamenten hervor, in denen man auf diese Weise den epithelialen Anteil ungemein anschaulich darzustellen vermag. Auch die Bakterien und Kokken nehmen natürlich den Farbstoff gut an. Im übrigen bin ich jedoch bei der ursprünglichen Quensellösung verblieben, schon aus dem Grunde, weil wenigstens bei den von mir bisher angewandten Fuchsinmischungen sehr leicht Niederschläge sich bilden, die die Schönheit des Bildes wesentlich beeinträchtigen. 